\title{
Some Exact Solutions of Boundary Layer Flows along a Vertical Plate with Buoyancy Forces Combined with Lorentz Forces under Uniform Suction
}

\author{
Asterios Pantokratoras \\ Department of Civil Engineering, School of Engineering, Democritus University of Thrace, \\ 67100 Xanthi, Greece \\ Correspondence should be addressed to Asterios Pantokratoras, apantokr@civil.duth.gr \\ Received 19 September 2007; Revised 2 May 2008; Accepted 7 August 2008 \\ Recommended by Horst Ecker \\ Exact analytical solutions of boundary layer flows along a vertical porous plate with uniform \\ suction are derived and presented in this paper. The solutions concern the Blasius, Sakiadis, \\ and Blasius-Sakiadis flows with buoyancy forces combined with either MHD Lorentz or EMHD \\ Lorentz forces. In addition, some exact solutions are presented specifically for water in the \\ temperature range of $0^{\circ} \mathrm{C} \leq T \leq 8^{\circ} \mathrm{C}$, where water density is nearly parabolic. Except for their \\ use as benchmarking means for testing the numerical solution of the Navier-Stokes equations, the \\ presented exact solutions with EMHD forces have use in flow separation control in aeronautics \\ and hydronautics, whereas the MHD results have applications in process metallurgy and fusion \\ technology. These analytical solutions are valid for flows with strong suction.
}

Copyright (c) 2008 Asterios Pantokratoras. This is an open access article distributed under the Creative Commons Attribution License, which permits unrestricted use, distribution, and reproduction in any medium, provided the original work is properly cited.

\section{Introduction}

Free convection along a vertical plate with mass transfer at the wall has been studied by many authors in the past. Eichhorn [1] was the first to study the effect of suction and injection on free convective flow. He considered power-law variation of plate temperature and transpiration velocity under which self-similar solutions of the governing equations are possible. For the case of isothermal plate with uniform blowing or suction, similarity does not exist. For the latter problem, Sparrow and Cess [2] provided approximate series solutions valid near the plate leading edge for $\operatorname{Pr}=0.72$. This problem was considered in more detail by Merkin [3] who obtained asymptotic solutions, valid at large distances from the leading edge. The next-order corrections to the boundary layer solution for this problem, concerning gases, were obtained by Clarke [4] who did not invoke the usual Boussinesq approximation. The solutions for strong suction and blowing on general body shapes which admit a similarity solution have been given by Merkin [5]. Parikh et al. [6] 
studied both numerically and experimentally the problem of air $(\operatorname{Pr}=0.7)$ free convection over an isothermal porous vertical plate with uniform transpiration taking into account the air variable physical properties. Minkowycz and Sparrow [7] using the local nonsimilarity method presented solutions for a wide range of Pr numbers. Vedhanayagam et al. [8] presented a transformation of the equations for general blowing and wall temperature variations, as well as results for the isothermal plate with uniform blowing. A solution to the constant plate temperature with uniform air blowing, based on the film model, has been derived by Brouwers [9]. In a subsequent paper, Brouwers [10], using the film model, derived a thermal correction factor and a novel friction correction factor which were applied to free convection along a vertical porous plate. The problem of blowing and suction on the free convection over a vertical plate with a given wall heat flux has been considered by Chaudhary and Merkin [11] who presented results valid for $\operatorname{Pr}=1$. Merkin [12] considered again the problem of free convection flow over a vertical plate with prescribed temperature, and presented results for variable transpiration velocities for $\operatorname{Pr} 1$ and 7.

In all of the above works, the buoyant force is produced by the temperature difference between the plate and the ambient fluid. Another kind of vertical force which resembles the buoyant force is the electromagnetohydrodynamic (EMHD) Lorentz force which acts parallel to the plate either assisting or opposing the flow. The EMHD Lorentz force can be generated by a stripwise arrangement of flush mounted electrodes and permanent magnets. Gailitis and Lielausis [13] were probably the first to propose the use of the EMHD Lorentz force for flow control over a plate. The idea of using the EMHD Lorentz force for flow control by Gailitis and Lielausis was later abandoned and only recently attracted new attention [14-17]. In addition, in last years much investigation on flow control using the EMHD Lorentz force was conducted at the Rossendorf Institute and the Institute for Aerospace Engineering in Dresden, Germany [18-22].

Magnetohydrodynamics (MHD) is the field of fluid mechanics that encompasses the phenomena arising when a magnetic field is applied to an electrically conducting fluid. Air, water, and especially liquid metals (lithium, mercury, and sodium) are electrically conducting fluids. The effect of an applied magnetic field on heat transfer in external flows has been investigated mainly for the cases of flat plate boundary layer and blunt body stagnation point flows. The works published in these areas appeared in the late 1950's and early 1960's with application to space-vehicle surface heating upon reentry. MHD is also applied to fusion technology [23].

The problem of flow along a vertical, stationary, isothermal plate of an electrically conducting fluid under a horizontal magnetic field is a classical problem in magnetohydrodynamics and has been treated for the first time by Sparrow and Cess [24]. Riley [25] and Kuiken [26] have reexamined the problem in order to give exact solutions, but their attempts to use the method of matched asymptotic expansions encountered difficulties. The first complete exact results for this problem have been given by Wilks [27] for $\operatorname{Pr}=0.72$.

In all of the above works, the vertical plate and the ambient fluid were motionless; that is, the problem treated was pure free convection. The problem of fluid flow along a stationary, impermeable, horizontal plate situated in a fluid stream moving with constant velocity is a classical problem of fluid mechanics that has been solved for the first time in 1908 by Blasius [28]. In this problem, the fluid motion is produced by the free stream. A similar problem occurs when the plate moves with constant velocity in a calm fluid. This problem has been treated for the first time by Sakiadis [29]. MHD flows along a moving plate in viscoelastic and micropolar fluids are treated in [30-34]. The combination of a moving vertical plate within 


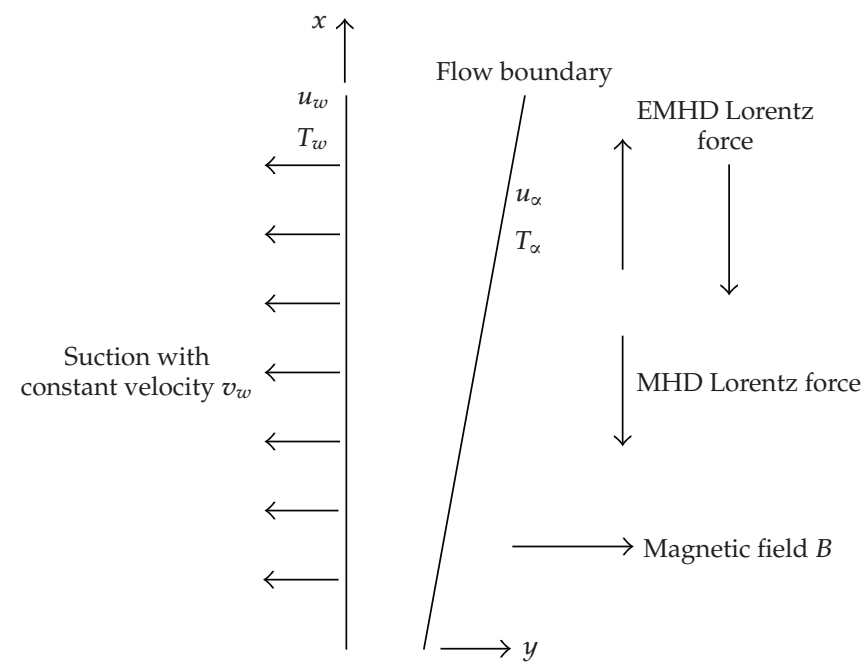

Figure 1: The flow configuration and coordinate system.

a vertical free stream with the existence of a vertical buoyancy force is called here SakiadisBlasius-buoyant flow.

The purpose of the present paper is to present some new exact analytical solutions for the Sakiadis-Blasius-buoyant flow over a vertical plate with uniform suction with either EMHD Lorentz or MHD Lorentz forces. Exact solutions of the Navier-Stokes equations are important for two reasons [35]. Owing to their uniform validity, the basic phenomena described by them can be more closely studied. In addition, the exact solutions serve as standards for checking the accuracies of the many approximate methods, whether they are numerical, asymptotic, or empirical. Current computer technology makes the complete numerical integration of the Navier-Stoles equations feasible. However, the accuracy of the results can only be ascertained by comparison with an exact solution.

\section{The mathematical model}

Consider the flow along a vertical plate with $u$ and $v$ denoting, respectively, the velocity components in the $x$ and $y$ directions, where $x$ is the coordinate along the plate and $y$ is the coordinate perpendicular to $x$ (see Figure 1). For steady two-dimensional flow, the boundary layer equations with constant fluid properties and linear relationship between density and temperature are as follows:

continuity equation:

$$
\frac{\partial u}{\partial x}+\frac{\partial v}{\partial y}=0
$$

momentum equation:

$$
u \frac{\partial u}{\partial x}+v \frac{\partial u}{\partial y}=v \frac{\partial^{2} u}{\partial y^{2}}+g \beta\left(T-T_{\infty}\right)
$$


energy equation:

$$
u \frac{\partial T}{\partial x}+v \frac{\partial T}{\partial y}=\lambda \frac{\partial^{2} T}{\partial y^{2}}
$$

where $v$ is the fluid kinematic viscosity, $g$ is the gravitational acceleration, $\beta$ is the volumetric expansion coefficient, $T$ is the fluid temperature, and $\lambda$ is the fluid thermal diffusivity.

When the suction velocity is very strong, (2.1)-(2.3) take the following forms [36, page 297]:

continuity equation:

$$
\frac{\partial v}{\partial y}=0
$$

momentum equation:

$$
v \frac{\partial u}{\partial y}=v \frac{\partial^{2} u}{\partial y^{2}}+g \beta\left(T-T_{\infty}\right)
$$

energy equation:

$$
v \frac{\partial T}{\partial y}=\lambda \frac{\partial^{2} T}{\partial y^{2}}
$$

It follows from (2.4) that $v=v_{w}=$ constant and the momentum and energy equations take the following forms:

momentum equation:

$$
v \frac{\partial^{2} u}{\partial y^{2}}-v_{w} \frac{\partial u}{\partial y}=-g \beta\left(T-T_{\infty}\right)
$$

energy equation:

$$
\lambda \frac{\partial^{2} T}{\partial y^{2}}-v_{w} \frac{\partial T}{\partial y}=0
$$

For combined Sakiadis-Blasius flow, the boundary conditions are as follows:

$$
\begin{aligned}
& \text { at } y=0: \quad u=u_{w}, \quad v=v_{w}, \quad T=T_{w}, \\
& \text { as } y \longrightarrow \infty, \quad u=u_{\infty}, \quad T=T_{\infty} .
\end{aligned}
$$

In the present work, the suction velocity $v_{w}$ is always negative. 


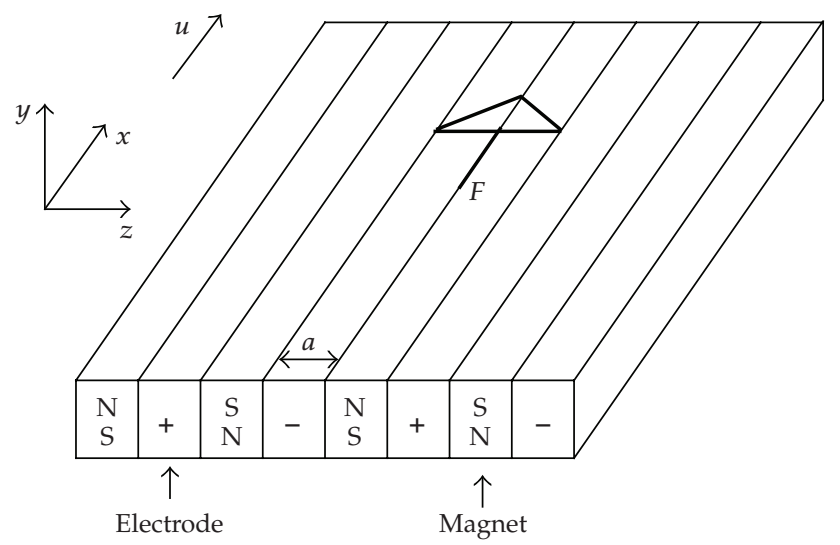

Figure 2: Arrangement of electrodes and magnets for the creation of an EMHD Lorentz force $F$ in the flow along a flat plate [20].

The energy equation (2.8) is independent of the momentum equation, and its solution [36, page 207] is

$$
\frac{T-T_{\infty}}{T_{w}-T_{\infty}}=\exp \left(\frac{v_{w} y}{\lambda}\right)
$$

\section{Results and discussion}

\subsection{Sakiadis-Blasius flow with buoyancy forces and EMHD Lorentz forces}

It is assumed that, except for the buoyancy force, an EMHD Lorentz force acts parallel to the plate. The EMHD Lorentz force can be generated by a stripwise arrangement of flush mounted electrodes and permanent magnets as sketched in Figure 2. For more information see Weier [20]. Then, the momentum equation (2.7) takes the following form:

$$
v \frac{\partial^{2} u}{\partial y^{2}}-v_{w} \frac{\partial u}{\partial y}=-g \beta\left(T-T_{\infty}\right)-\frac{\pi j_{0} M_{0}}{8 \rho_{\infty}} \exp \left(-\frac{\pi}{a} y\right)
$$

where $j_{0}$ is the applied current density, $M_{0}$ is the magnetization of the permanent magnets, $\alpha$ is the width of magnets and electrodes, and $\rho_{\infty}$ is the ambient fluid density. It should be noted here that the EMHD Lorentz force can either assist or oppose the flow and is independent of the flow field. The last term in the momentum equation is the EMHD Lorentz force which assists the flow and decreases exponentially with $y$. Substituting the temperature difference from (2.10) into (3.1), we have

$$
v \frac{\partial^{2} u}{\partial y^{2}}-v_{w} \frac{\partial u}{\partial y}=-g \beta\left(T_{w}-T_{\infty}\right) \exp \left(\frac{v_{w}}{\lambda} y\right)-\frac{\pi j_{0} M_{0}}{8 \rho_{\infty}} \exp \left(-\frac{\pi}{a} y\right)
$$


Equation (3.2) is a linear differential equation of second order and has the following exact analytical solution for the Sakiadis-Blasius-buoyant-EMHD flow:

$$
\frac{u-u_{\infty}}{u_{w}-u_{\infty}}=(1+G+Z) \exp \left(\frac{v_{w}}{v} y\right)-G \exp \left(\frac{v_{w}}{\lambda} y\right)-Z \exp \left(-\frac{\pi}{a} y\right)
$$

where $G$ is the buoyancy parameter:

$$
G=\frac{\lg \beta\left(T_{w}-T_{\infty}\right)}{\left(u_{w}-u_{\infty}\right) v_{w}^{2}(\operatorname{Pr}-1)}
$$

and $\mathrm{Z}$ is the Lorentz parameter:

$$
Z=\frac{j_{0} M_{0} a^{2}}{8 \rho_{\infty}\left(u_{w}-u_{\infty}\right)\left(\pi v+a v_{w}\right)}
$$

The Prandtl number is

$$
\operatorname{Pr}=\frac{v}{\lambda}
$$

Both parameters $G$ and $Z$ are dimensionless. The absolute wall shear stress is

$$
\tau_{w}=\rho_{\infty}\left(u_{w}-u_{\infty}\right) v_{w}-\frac{\mu g \beta\left(T_{w}-T_{\infty}\right)}{v_{w} \operatorname{Pr}}+\frac{j_{0} M_{0} a}{8}
$$

while the dimensionless skin-friction coefficient is

$$
c_{f}=\frac{\tau_{w}}{\rho_{\infty}\left(u_{w}-u_{\infty}\right) v_{w}}=1+G(1-\operatorname{Pr})+Z\left(\frac{\pi}{\operatorname{Re}}+1\right)
$$

where Re is the suction Reynolds number:

$$
\operatorname{Re}=\frac{a v_{w}}{v}
$$

It should be noted here that this is the first work on fluid mechanics which uses both EMHD Lorentz forces and suction simultaneously, and therefore the above Reynolds number, using as characteristic length the distance between the magnets, appears for the first time in the literature.

When

$$
Z=-1-G(1-\operatorname{Pr})\left(\frac{\pi}{\operatorname{Re}}+1\right)^{-1}
$$




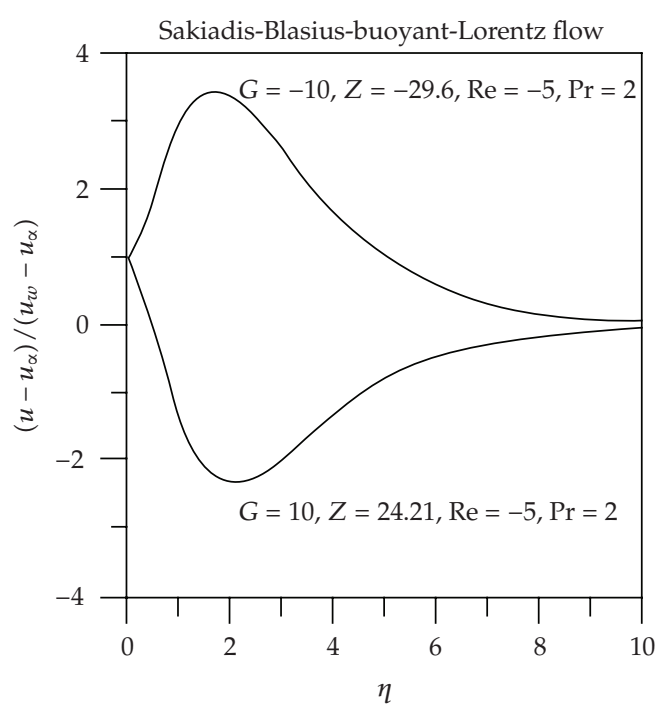

(a)

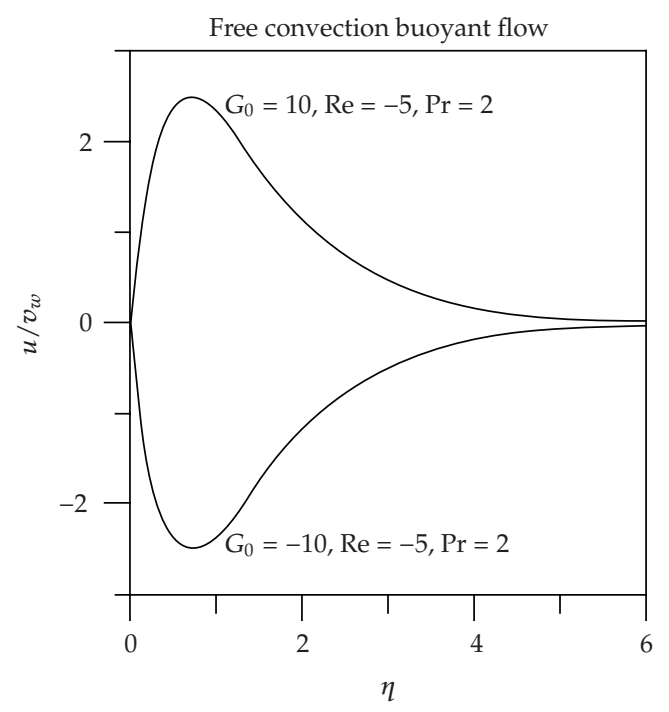

(c)

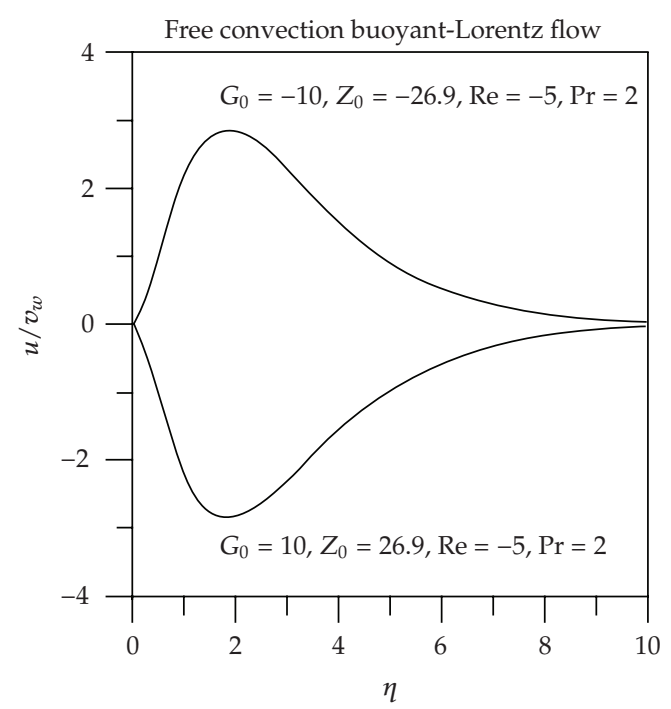

(b)

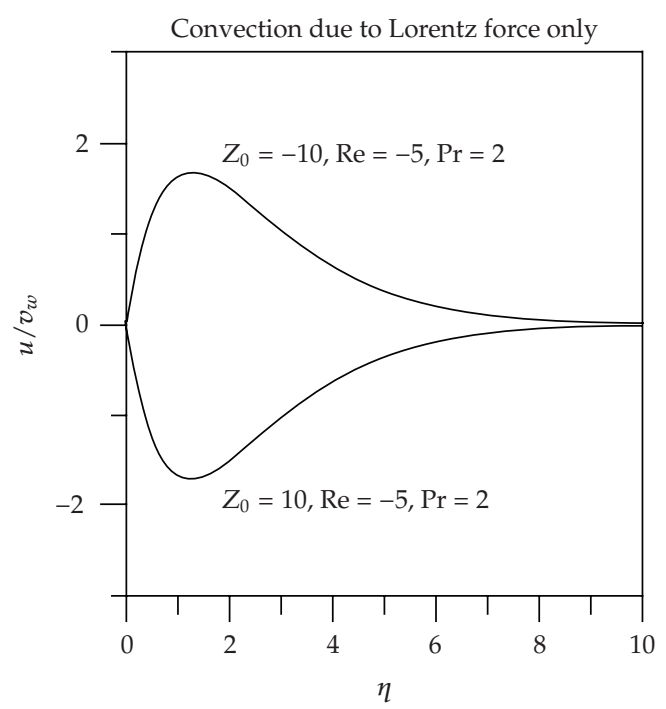

(d)

Figure 3: Dimensionless velocity distribution for different kinds of flow with buoyancy forces and Lorentz forces. In cases (a) and (b), the wall shear stress is zero.

the wall shear stress is zero. In Figure 3(a), two velocity profiles are shown for which the wall shear stress is zero ((3.10) is valid). The transverse coordinate $\eta$ is

$$
\eta=-\frac{v_{w}}{v} y
$$

and the two curves meet the vertical axis orthogonally. 
When the free-stream velocity is zero, we have the Sakiadis-buoyant-EMHD flow:

$$
\frac{u}{u_{w}}=\left(1+G_{s}+Z_{s}\right) \exp \left(\frac{v_{w}}{v} y\right)-G_{s} \exp \left(\frac{v_{w}}{\lambda} y\right)-Z_{s} \exp \left(-\frac{\pi}{a} y\right),
$$

where

$$
\begin{aligned}
G_{s} & =\frac{\lambda g \beta\left(T_{w}-T_{\infty}\right)}{u_{w} v_{w}^{2}(\operatorname{Pr}-1)}, \\
Z_{S} & =\frac{j_{0} M_{0} a^{2}}{8 \rho_{\infty} u_{w}\left(\pi v+a v_{w}\right)} .
\end{aligned}
$$

The absolute wall shear stress is

$$
\tau_{w}=\rho_{\infty} u_{w} v_{w}-\frac{\mu g \beta\left(T_{w}-T_{\infty}\right)}{v_{w} \operatorname{Pr}}+\frac{j_{0} M_{0} a}{8}
$$

while the dimensionless skin-friction coefficient is

$$
c_{f}=\frac{\tau_{w}}{\rho u_{w} v_{w}}=1+G_{s}(1-\operatorname{Pr})+Z_{s}\left(\frac{\pi}{\operatorname{Re}}+1\right) .
$$

When

$$
Z_{s}=-1-G_{s}(1-\operatorname{Pr})\left(\frac{\pi}{\operatorname{Re}}+1\right)^{-1}
$$

the wall shear stress is zero.

When the plate is motionless, we have the Blasius-buoyant-EMHD flow:

$$
\frac{u}{u_{\infty}}=1-\left(1-G_{b}-Z_{b}\right) \exp \left(\frac{v_{w}}{v} y\right)-G_{b} \exp \left(\frac{v_{w}}{\lambda} y\right)-Z_{b} \exp \left(-\frac{\pi}{a} y\right)
$$

where

$$
\begin{aligned}
G_{b} & =\frac{\lambda g \beta\left(T_{w}-T_{\infty}\right)}{u_{\infty} v_{w}^{2}(\operatorname{Pr}-1)} \\
Z_{b} & =\frac{j_{0} M_{0} a^{2}}{8 \rho_{\infty} u_{\infty}\left(\pi v+a v_{w}\right)} .
\end{aligned}
$$

The absolute wall shear stress is

$$
\tau_{w}=-\rho_{\infty} u_{\infty} v_{w}-\frac{\mu g \beta\left(T_{w}-T_{\infty}\right)}{v_{w} \operatorname{Pr}}+\frac{j_{0} M_{0} a}{8}
$$


while the dimensionless skin-friction coefficient is

$$
c_{f}=\frac{\tau_{w}}{\rho_{\infty} u_{\infty} v_{w}}=-1+G_{b}(1-\operatorname{Pr})+Z_{b}\left(\frac{\pi}{\operatorname{Re}}+1\right) .
$$

When

$$
Z_{b}=1-G_{b}(1-\operatorname{Pr})\left(\frac{\pi}{\operatorname{Re}}+1\right)^{-1}
$$

the wall shear stress is zero.

When the plate is motionless and the free-stream velocity is zero, we have pure free convection and the analytical solution becomes

$$
\frac{u}{v_{w}}=\left(G_{0}+Z_{0}\right) \exp \left(\frac{v_{w}}{v} y\right)-G_{0} \exp \left(\frac{v_{w}}{l} y\right)-Z_{0} \exp \left(-\frac{\pi}{a} y\right)
$$

where

$$
\begin{aligned}
G_{0} & =\frac{\lg \beta\left(T_{w}-T_{\infty}\right)}{v_{w}^{3}(\operatorname{Pr}-1)} \\
Z_{0} & =\frac{j_{0} M_{0} a^{2}}{8 \rho_{\infty} v_{w}\left(\pi v+a v_{w}\right)}
\end{aligned}
$$

In (3.22), the longitudinal velocity $u$ is nondimensionalized with suction velocity $v_{w}$ because in the above problem the suction velocity is the apparent characteristic velocity of the flow.

The absolute wall shear stress is

$$
\tau_{w}=-\frac{\mu g \beta\left(T_{w}-T_{\infty}\right)}{v_{w} \operatorname{Pr}}+\frac{j_{0} M_{0} a}{8}
$$

while the dimensionless skin-friction coefficient is

$$
c_{f}=\frac{\tau_{w}}{\rho v_{w}^{2}}=G_{0}(1-\operatorname{Pr})+Z_{0}\left(\frac{\pi}{\operatorname{Re}}+1\right) .
$$

When

$$
Z_{0}=G_{0}(\operatorname{Pr}-1)\left(\frac{\pi}{\operatorname{Re}}+1\right)^{-1}
$$

the wall shear stress is zero. In Figure 3(b), two velocity profiles are shown for which the wall shear stress is zero. The velocity profiles near the plate for cases (a) and (b) are shown in Figure 4. 


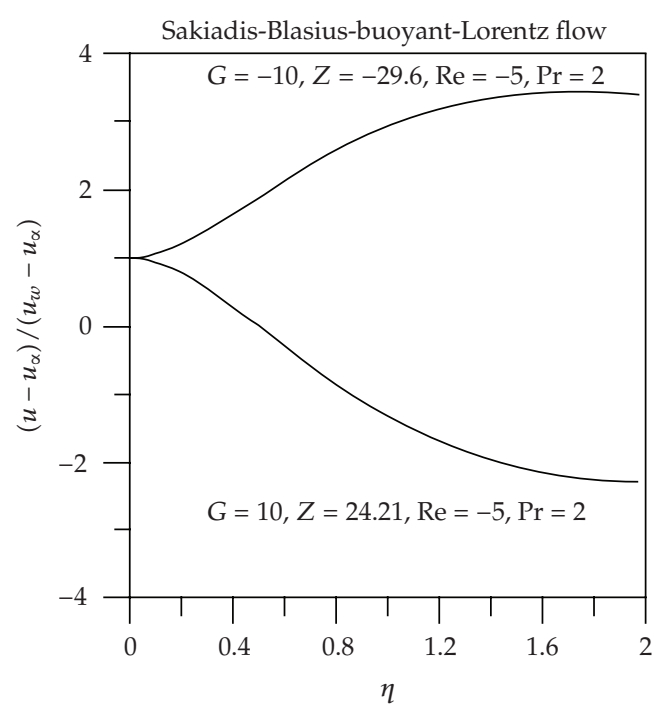

(a)

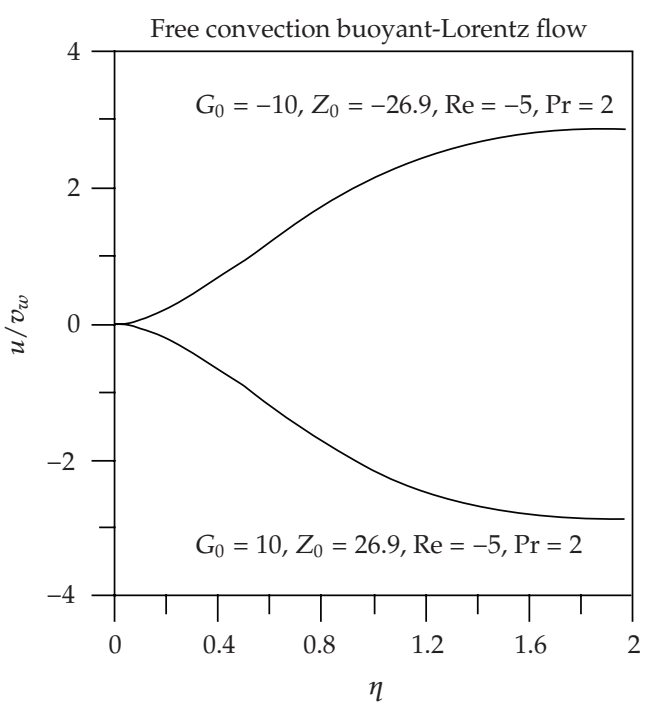

(b)

Figure 4: The velocity profiles near the plate for cases (a) and (b) where it is clearly shown that the wall shear stress is zero.

When there is no Lorentz force, we have convection due to buoyancy force only and velocity is given by

$$
\frac{u}{v_{w}}=G_{0} \exp \left(\frac{v_{w}}{v} y\right)-G_{0} \exp \left(\frac{v_{w}}{l} y\right)
$$

The absolute wall shear stress is

$$
\tau_{w}=-\frac{\mu g \beta\left(T_{w}-T_{\infty}\right)}{v_{w} \operatorname{Pr}}
$$

while the dimensionless skin-friction coefficient is

$$
c_{f}=\frac{\tau_{w}}{\rho v_{w}^{2}}=G_{0}(1-\operatorname{Pr})
$$

When there is no buoyancy force, we have convection due to EMHD Lorentz force only and velocity is given by

$$
\frac{u}{v_{w}}=Z_{0} \exp \left(\frac{v_{w}}{v} y\right)-Z_{0} \exp \left(-\frac{\pi}{a} y\right)
$$

This is a new "strange" kind of convection caused by the EMHD Lorentz force only. The physical meaning of the above equation is as follows. Let us suppose that we have a porous plate where fluid is removed with uniform suction. Although the plate is motionless and the 
ambient fluid is at rest, a boundary layer forms along the plate due to the act of the Lorentz force which is independent of the flow.

The absolute value of wall shear stress is

$$
\tau_{w}=\frac{j_{0} M_{0} a}{8}
$$

while the dimensionless skin-friction coefficient is

$$
c_{f}=\frac{\tau_{w}}{\rho v_{w}^{2}}=Z_{0}\left(\frac{\pi}{\operatorname{Re}}+1\right)
$$

It is surprising that the absolute wall shear stress is independent of viscosity and suction velocity.

\subsection{Sakiadis-Blasius flow with buoyancy forces and EMHD Lorentz forces in water near $4^{\circ} \mathrm{C}$}

The momentum equation with EMHD Lorentz force and the buoyancy force expressed in density is

$$
v \frac{\partial^{2} u}{\partial y^{2}}-v_{w} \frac{\partial u}{\partial y}=-g \frac{\rho_{\infty}-\rho}{\rho_{\infty}}-\frac{\pi j_{0} M_{0}}{8 \rho_{\infty}} \exp \left(-\frac{\pi}{a} y\right)
$$

The buoyancy term can be calculated from the following equation [37]:

$$
\frac{\rho_{\infty}-\rho}{\rho_{\infty}}=\gamma\left(T-T_{\infty}\right)^{2}
$$

where $\gamma=0.8 \times 10^{-5}\left({ }^{\circ} \mathrm{C}\right)^{-2}$. Equation (3.34) is valid for the temperature range of $0^{\circ} \mathrm{C} \leq T \leq 8^{\circ} \mathrm{C}$, and $T_{\infty}=4^{\circ} \mathrm{C}$ where the variation of water density is nearly parabolic. Therefore, (3.33) becomes

$$
v \frac{\partial^{2} u}{\partial y^{2}}-v_{w} \frac{\partial u}{\partial y}=-g \gamma\left(T-T_{\infty}\right)^{2}-\frac{\pi j_{0} M_{0}}{8 \rho} \exp \left(-\frac{\pi}{a} y\right)
$$

Substituting the temperature difference from (2.10) into (3.35), we have

$$
v \frac{\partial^{2} u}{\partial y^{2}}-v_{w} \frac{\partial u}{\partial y}=-g \gamma\left(T_{w}-T_{\infty}\right)^{2} \exp \left(\frac{2 v_{w}}{\lambda} y\right)-\frac{\pi j_{0} M_{0}}{8 \rho} \exp \left(-\frac{\pi}{a} y\right)
$$

The exact solution of this equation is

$$
\frac{u-u_{\infty}}{u_{w}-u_{\infty}}=(1+W+Z) \exp \left(\frac{v_{w}}{v} y\right)-W \exp \left(\frac{2 v_{w}}{\lambda} y\right)-Z \exp \left(-\frac{\pi}{a} y\right)
$$


where

$$
W=\frac{\lg \gamma\left(T_{w}-T_{\infty}\right)^{2}}{2\left(u_{w}-u_{\infty}\right) v_{w}^{2}(2 \operatorname{Pr}-1)} .
$$

The absolute wall shear stress is

$$
\tau_{w}=\rho_{\infty}\left(u_{w}-u_{\infty}\right) v_{w}-\frac{\mu g \gamma\left(T_{w}-T_{\infty}\right)^{2}}{2 v_{w} \operatorname{Pr}}+\frac{j_{0} M_{0} a}{8}
$$

while the dimensionless skin-friction coefficient is

$$
c_{f}=\frac{\tau_{w}}{\rho_{\infty}\left(u_{w}-u_{\infty}\right) v_{w}}=1+W(1-2 \operatorname{Pr})+Z\left(\frac{\pi}{\operatorname{Re}}+1\right) .
$$

The wall shear stress becomes zero when

$$
Z=-1+W(2 \operatorname{Pr}-1)\left(\frac{\pi}{\operatorname{Re}}+1\right)^{-1}
$$

When the free-stream velocity is zero, we have the Sakiadis-buoyant-EMHD flow:

$$
\frac{u}{u_{w}}=\left(1+W_{s}+Z_{s}\right) \exp \left(\frac{v_{w}}{v} y\right)-W_{s} \exp \left(\frac{2 v_{w}}{\lambda} y\right)-Z_{s} \exp \left(-\frac{\pi}{a} y\right)
$$

where

$$
W_{s}=\frac{\lambda g \gamma\left(T_{w}-T_{\infty}\right)^{2}}{2 u_{w} v_{w}^{2}(2 \operatorname{Pr}-1)}
$$

The absolute wall shear stress is

$$
\tau_{w}=\rho_{\infty} u_{w} v_{w}-\frac{\mu g \gamma\left(T_{w}-T_{\infty}\right)^{2}}{2 v_{w} \operatorname{Pr}}+\frac{j_{0} M_{0} a}{8}
$$

while the dimensionless skin-friction coefficient is

$$
c_{f}=\frac{\tau_{w}}{\rho_{\infty} u_{w} v_{w}}=1+W_{s}(1-2 \operatorname{Pr})+Z_{s}\left(\frac{\pi}{\operatorname{Re}}+1\right) .
$$

The wall shear stress becomes zero when

$$
Z_{s}=-1+W_{s}(2 \operatorname{Pr}-1)\left(\frac{\pi}{\operatorname{Re}}+1\right)^{-1}
$$


When the plate is motionless, we have the Blasius-buoyant-EMHD flow:

$$
\frac{u}{u_{\infty}}=1-\left(1-W_{b}-Z_{b}\right) \exp \left(\frac{v_{w}}{v} y\right)-W_{b} \exp \left(\frac{2 v_{w}}{\lambda} y\right)-Z_{b} \exp \left(-\frac{\pi}{a} y\right),
$$

where

$$
W_{b}=\frac{\lg \gamma\left(T_{w}-T_{\infty}\right)^{2}}{2 u_{\infty} v_{w}^{2}(2 \operatorname{Pr}-1)}
$$

The absolute wall shear stress is

$$
\tau_{w}=-\rho_{\infty} u_{\infty} v_{w}-\frac{\mu g \gamma\left(T_{w}-T_{\infty}\right)^{2}}{2 v_{w} \operatorname{Pr}}+\frac{j_{0} M_{0} a}{8}
$$

while the dimensionless skin-friction coefficient is

$$
c_{f}=\frac{\tau_{w}}{\rho u_{\infty} v_{w}}=-1+W_{b}(1-2 \operatorname{Pr})+Z_{b}\left(\frac{\pi}{\operatorname{Re}}+1\right) .
$$

The wall shear stress becomes zero when

$$
Z_{b}=1+W_{b}(2 \operatorname{Pr}-1)\left(\frac{\pi}{\operatorname{Re}}+1\right)^{-1}
$$

When the plate is motionless and the free-stream velocity is zero, we have pure free convection and the analytical solution becomes

$$
\frac{u}{v_{w}}=\left(W_{0}+Z_{0}\right) \exp \left(\frac{v_{w}}{v} y\right)-W_{0} \exp \left(\frac{2 v_{w}}{\lambda} y\right)-Z_{0} \exp \left(-\frac{\pi}{a} y\right)
$$

where

$$
W_{0}=\frac{\lg \gamma\left(T_{w}-T_{\infty}\right)^{2}}{2 v_{w}^{3}(2 \operatorname{Pr}-1)} .
$$

The absolute wall shear stress is

$$
\tau_{w}=-\frac{\mu g \gamma\left(T_{w}-T_{\infty}\right)^{2}}{2 v_{w} \operatorname{Pr}}+\frac{j_{0} M_{0} a}{8},
$$

while the dimensionless skin-friction coefficient is

$$
c_{f}=\frac{\tau_{w}}{\rho v_{w}^{2}}=W_{0}(1-2 \operatorname{Pr})+Z_{0}\left(\frac{\pi}{\operatorname{Re}}+1\right) .
$$


The wall shear stress becomes zero when

$$
Z_{0}=W_{0}(2 \operatorname{Pr}-1)\left(\frac{\pi}{\operatorname{Re}}+1\right)^{-1} .
$$

When there is no EMHD Lorentz force, we have convection due to buoyancy force only and velocity is given by

$$
\frac{u}{v_{w}}=W_{0} \exp \left(\frac{v_{w}}{v} y\right)-W_{0} \exp \left(\frac{2 v_{w}}{\curlywedge} y\right)
$$

The absolute wall shear stress is

$$
\tau_{w}=-\frac{\mu g \gamma\left(T_{w}-T_{\infty}\right)^{2}}{2 v_{w} \operatorname{Pr}}
$$

while the dimensionless skin-friction coefficient is

$$
c_{f}=\frac{\tau_{w}}{\rho v_{w}^{2}}=W_{0}(1-2 \operatorname{Pr})
$$

\subsection{Magnetohydrodynamic free convection with uniform suction}

The momentum equation for this problem is [24]

$$
v \frac{\partial^{2} u}{\partial y^{2}}-v_{w} \frac{\partial u}{\partial y}-\frac{\sigma B^{2}}{\rho_{\infty}} u=-g \beta\left(T_{w}-T_{\infty}\right) \exp \left(\frac{v_{w}}{\lambda} y\right),
$$

where $\sigma$ is the fluid electrical conductivity and $B$ is the strength of magnetic field which is applied transversely to the flow (see Figure 1). The MHD Lorentz force $\sigma B^{2} u / \rho_{\infty}$ always opposes the flow.

The analytical solution of the Sakiadis-buoyant-MHD flow for a moving plate has been produced by Vajravelu [38]. Here we will give the analytical solution for a motionless plate and motionless ambient fluid (pure free convection). The exact solution is

$$
\frac{u}{v_{w}}=G_{m}\left(\exp \left(A \frac{v_{w}}{v} y\right)-\exp \left(\frac{v_{w}}{\lambda} y\right)\right)
$$

Where $A=0.5\left(1+(1+4 M)^{1 / 2}\right), M$ is the Hartmann number:

$$
M=\frac{\sigma B^{2} v}{\rho_{\infty} v_{w}^{2}},
$$

and $G_{m}$ is the buoyancy parameter:

$$
G_{m}=\frac{v g \beta\left(T_{w}-T_{\infty}\right)}{v_{w}^{3}\left(\operatorname{Pr}^{2}-\operatorname{Pr}-M\right)}
$$


The absolute wall shear stress is

$$
\tau_{w}=\frac{\mu g \beta\left(T_{w}-T_{\infty}\right)(A-\operatorname{Pr})}{v_{w}\left(\operatorname{Pr}^{2}-\operatorname{Pr}-M\right)},
$$

while the dimensionless skin-friction coefficient is

$$
c_{f}=\frac{\tau_{w}}{\rho_{\infty} v_{w}^{2}}=G_{m}(A-\operatorname{Pr})
$$

\subsection{Magnetohydrodynamic Sakiadis flow in water near $4^{\circ} \mathrm{C}$}

The momentum equation with magnetic field and buoyancy force expressed in density is

$$
v \frac{\partial^{2} u}{\partial y^{2}}-v_{w} \frac{\partial u}{\partial y}-\frac{\sigma B^{2}}{\rho_{\infty}} u=-g \frac{\rho_{\infty}-\rho}{\rho_{\infty}} .
$$

Taking into account (3.34), we have

$$
v \frac{\partial^{2} u}{\partial y^{2}}-v_{w} \frac{\partial u}{\partial y}-\frac{\sigma B^{2}}{\rho_{\infty}} u=-g \gamma\left(T-T_{\infty}\right)^{2}
$$

Substituting the temperature difference from (2.10) into (3.67), we have

$$
v \frac{\partial^{2} u}{\partial y^{2}}-v_{w} \frac{\partial u}{\partial y}-\frac{\sigma B^{2}}{\rho_{\infty}} u=-g \gamma\left(T_{w}-T_{\infty}\right)^{2} \exp \left(\frac{2 v_{w}}{\ell} y\right)
$$

Equation (3.68) has the following analytical solution for Sakiadis-buoyant-MHD flow:

$$
\frac{u}{u_{w}}=\left(1+G_{s w}\right) \exp \left(A \frac{v_{w}}{v} y\right)-G_{s w} \exp \left(\frac{2 v_{w}}{\lambda} y\right)
$$

where

$$
G_{s w}=\frac{v g r\left(T_{w}-T_{\infty}\right)^{2}}{u_{w} v_{w}^{2}\left(4 \operatorname{Pr}^{2}-2 \operatorname{Pr}-M\right)}
$$

The absolute wall shear stress is

$$
\tau_{w}=\rho_{\infty} u_{w} v_{w} A+\frac{\mu g r\left(T_{w}-T_{\infty}\right)^{2}(A-2 \operatorname{Pr})}{v_{w}\left(4 \operatorname{Pr}^{2}-2 \operatorname{Pr}-M\right)},
$$

while the dimensionless skin-friction coefficient is

$$
c_{f}=\frac{\tau_{w}}{\rho_{\infty} u_{w} v_{w}}=A+G_{s w}(A-2 \operatorname{Pr}) .
$$


When the plate is motionless, we have pure free convection and velocity is given by

$$
\frac{u}{v_{w}}=G_{0 w} \exp \left(A \frac{v_{w}}{v} y\right)-G_{0 w} \exp \left(\frac{2 v_{w}}{\lambda} y\right)
$$

where

$$
G_{0 w}=\frac{v g \gamma\left(T_{w}-T_{\infty}\right)^{2}}{v_{w}^{3}\left(4 \operatorname{Pr}^{2}-2 \operatorname{Pr}-M\right)}
$$

The absolute wall shear stress is

$$
\tau_{w}=\frac{\mu g \gamma\left(T_{w}-T_{\infty}\right)^{2}(A-2 \operatorname{Pr})}{v_{w}\left(4 \operatorname{Pr}^{2}-2 \operatorname{Pr}-M\right)}
$$

while the dimensionless skin-friction coefficient is

$$
c_{f}=\frac{\tau_{w}}{\rho_{\infty} v_{w}^{2}}=G_{s w}(A-2 \operatorname{Pr}) .
$$

\section{Conclusions}

In this paper, the boundary layer buoyant flow along a vertical porous plate with uniform suction has been treated. Exact analytical solutions have been found for Blasius, Sakiadis, and combined Blasius-Sakiadis flows with MHD and EMHD Lorentz forces. A series of new dimensionless parameters $(G, Z, W, R e)$ are introduced for the presentation of the results in elegant form. The author believes that the results of the present work will enrich the list with the existing exact solutions of the Navier-Stokes equations and may help the investigation of flow separation control in aeronautics and hydronautics as well as the application of magnetohydrodynamics in industry.

\section{References}

[1] R. Eichhorn, "The effect of mass transfer on free convection," Journal of Heat Transfer, vol. 82C, pp. 260-263, 1960.

[2] E. M. Sparrow and R. D. Cess, "Free convection with blowing or suction," Journal of Heat Transfer, vol. 81C, pp. 387-389, 1961.

[3] J. H. Merkin, "Free convection with blowing and suction," International Journal of Heat and Mass Transfer, vol. 15, no. 5, pp. 989-999, 1972.

[4] J. F. Clarke, "Transpiration and natural convection: the vertical-flat-plate problem," Journal of Fluid Mechanics, vol. 57, no. 1, pp. 45-61, 1973.

[5] J. H. Merkin, "The effects of blowing and suction on free convection boundary layers," International Journal of Heat and Mass Transfer, vol. 18, no. 2, pp. 237-244, 1975.

[6] P. G. Parikh, R. J. Moffat, W. M. Kays, and D. Bershader, "Free convection over a vertical porous plate with transpiration," International Journal of Heat and Mass Transfer, vol. 17, no. 12, pp. 1465-1474, 1974.

[7] W. J. Minkowycz and E. M. Sparrow, "Numerical solution scheme for local nonsimilarity boundary layer analysis," Numerical Heat Trasnfer, Part A, vol. 1, no. 1, pp. 69-85, 1978.

[8] M. Vedhanayagam, R. A. Altenkirch, and R. Eichhorn, "A transformation of the boundary layer equations for free convection past a vertical flat plate with arbitrary blowing and wall temperature variations," International Journal of Heat and Mass Transfer, vol. 23, no. 9, pp. 1286-1288, 1980. 
[9] H. J. H. Brouwers, "The film model applied to free convection over a vertical plate with blowing or suction," International Journal of Heat and Mass Transfer, vol. 35, no. 7, pp. 1841-1844, 1992.

[10] H. J. H. Brouwers, "A film model for free convection over a vertical porous plate with blowing or suction," Heat and Mass Transfer, vol. 29, no. 1, pp. 17-26, 1993.

[11] M. A. Chaudhary and J. H. Merkin, "The effects of blowing and suction on free convection boundary layers on vertical surfaces with prescribed heat flux," Journal of Engineering Mathematics, vol. 27, no. 3, pp. 265-292, 1993.

[12] J. H. Merkin, "A note on the similarity equations arising in free convection boundary layers with blowing and suction," Zeitschrift für Angewandte Mathematik und Physik, vol. 45, no. 2, pp. 258-274, 1994.

[13] A. Gailitis and O. Lielausis, "On a possibility to reduce the hydrodynamic resistance of a plate in an electrolyte," Applied Magnetohydrodynamics, vol. 12, pp. 143-146, 1961.

[14] C. Henoch and J. Stace, "Experimental investigation of a salt water turbulent boundary layer modified by an applied streamwise magnetohydrodynamic body force," Physics of Fluids, vol. 7, no. 6, pp. 13711383, 1995.

[15] C. H. Crawford and G. E. Karniadakis, "Reynolds stress analysis of EMHD-controlled wall turbulence-part I: streamwise forcing," Physics of Fluids, vol. 9, no. 3, pp. 788-806, 1997.

[16] T. W. Berger, J. Kim, C. Lee, and J. Lim, "Turbulent boundary layer control utilizing the Lorentz force," Physics of Fluids, vol. 12, no. 3, pp. 631-649, 2000.

[17] E. Spong, J. A. Reizes, and E. Leonardi, "Efficiency improvements of electromagnetic flow control," International Journal of Heat and Fluid Flow, vol. 26, no. 4, pp. 635-655, 2005.

[18] O. Posdziech and R. Grundmann, "Electromagnetic control of seawater flow around circular cylinders," European Journal of Mechanics. B/Fluids, vol. 20, no. 2, pp. 255-274, 2001.

[19] T. Weier and G. Gerbeth, "Control of separated flows by time periodic Lorentz forces," European Journal of Mechanics, B/Fluids, vol. 23, no. 6, pp. 835-849, 2004.

[20] T. Weier, Elektromagnetische Stromungskontrolle mit wandparallelen Lorentzkraften in schwach leitfahigen Fluiden, dissertation, Technische Universitat Dresden, Dresden, Germany, 2005.

[21] G. Mutschke, G. Gerbeth, T. Albrecht, and R. Grundmann, "Separation control at hydrofoils using Lorentz forces," European Journal of Mechanics, B/Fluids, vol. 25, no. 2, pp. 137-152, 2006.

[22] T. Albrecht, R. Grundmann, G. Mutschke, and G. Gerbeth, "On the stability of the boundary layer subject to a wall-parallel Lorentz force," Physics of Fluids, vol. 18, no. 9, Article ID 098103, 4 pages, 2006.

[23] N. B. Morley, S. Smolentsev, L. Barleon, I. R. Kirillov, and M. Takahashi, "Liquid magnetohydrodynamics—recent progress and future directions for fusion," Fusion Engineering and Design, vol. 51-52, pp. 701-713, 2000.

[24] E. M. Sparrow and R. D. Cess, "The effect of a magnetic field on free convection heat transfer," International Journal of Heat and Mass Transfer, vol. 3, no. 4, pp. 267-274, 1961.

[25] N. Riley, "Magnetohydrodynamic free convection," Journal of Fluid Mechanics, vol. 18, no. 4, pp. 577586, 1964.

[26] H. K. Kuiken, "Magnetohydrodynamic free convection in a strong cross field," Journal of Fluid Mechanics, vol. 40, no. 1, pp. 21-38, 1970.

[27] G. Wilks, "Magnetohydrodynamic free convection about a semi-infinite vertical plate in a strong cross field," Zeitschrift für Angewandte Mathematik und Physik, vol. 27, no. 5, pp. 621-631, 1976.

[28] H. Blasius, "Grenzschichten in Flussigkeiten mit kleiner Reibung," Zeitschrift für Mathematik und Physik, vol. 56, no. 1, pp. 1-37, 1908.

[29] B. C. Sakiadis, "Boundary layer behavior on continuous solid surfaces-II: the boundary layer on a continuous flat surface," AIChE Journal, vol. 7, no. 2, pp. 221-225, 1961.

[30] M. A. Seddeek, "Flow of a magneto-micropolar fluid past a continuously moving plate," Physics Letters A, vol. 306, no. 4, pp. 255-257, 2003.

[31] N. T. Eldabe, E. F. Elshehawey, E. M. E. Elbarbary, and N. S. Elgazery, "Chebyshev finite difference method for MHD flow of a micropolar fluid past a stretching sheet with heat transfer," Applied Mathematics and Computation, vol. 160, no. 2, pp. 437-450, 2005.

[32] M. M. Rahman and M. A. Sattar, "Magnetohydrodynamic convective flow of a micropolar fluid past a continuously moving vertical porous plate in the presence of heat generation/absorption," Journal of Heat Transfer, vol. 128, no. 2, pp. 142-152, 2006.

[33] R. Cortell, "Effects of viscous dissipation and work done by deformation on the MHD flow and heat transfer of a viscoelastic fluid over a stretching sheet," Physics Letters A, vol. 357, no. 4-5, pp. 298-305, 2006. 
[34] R. Cortell, "MHD flow and mass transfer of an electrically conducting fluid of second grade in a porous medium over a stretching sheet with chemically reactive species," Chemical Engineering and Processing, vol. 46, no. 8, pp. 721-728, 2007.

[35] C. Y. Wang, "Exact solutions of the steady-state Navier-Stokes equations," Annual Review of Fluid Mechanics, vol. 23, no. 1, pp. 159-177, 1991.

[36] H. Schlichting and K. Gersten, Boundary Layer Theory, Springer, Berlin, Germany, 9th edition, 2003.

[37] S. L. Goren, "On free convection in water at $4^{\circ} \mathrm{C}^{\prime \prime}$ Chemical Engineering Science, vol. 21, no. 6-7, pp. 515-518, 1966.

[38] K. Vajravelu, "Hydromagnetic convection at a continuous moving surface," Acta Mechanica, vol. 72, no. 3-4, pp. 223-232, 1988. 


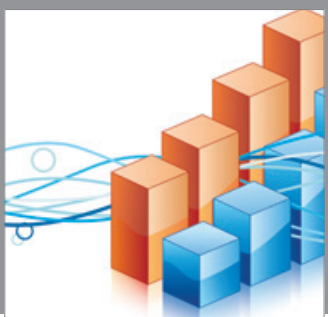

Advances in

Operations Research

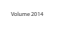

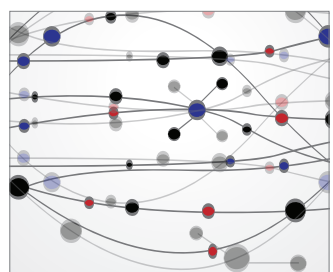

\section{The Scientific} World Journal
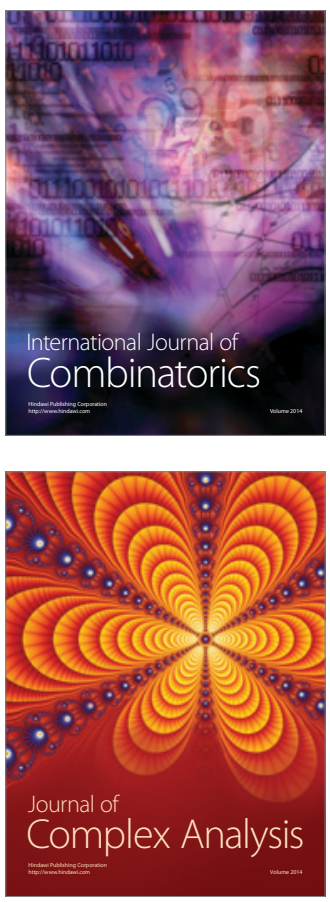

International Journal of

Mathematics and

Mathematical

Sciences
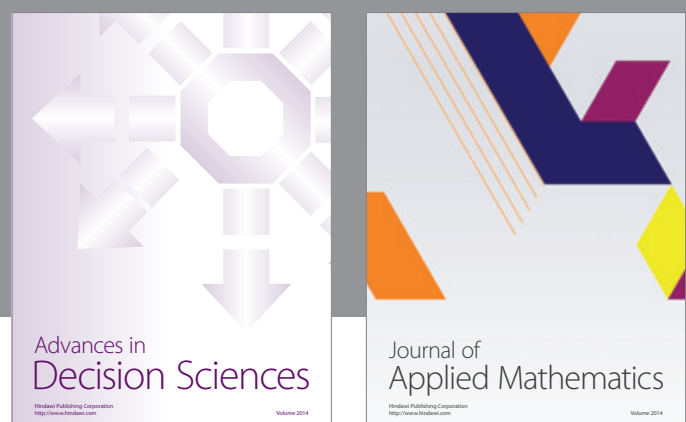

Journal of

Applied Mathematics
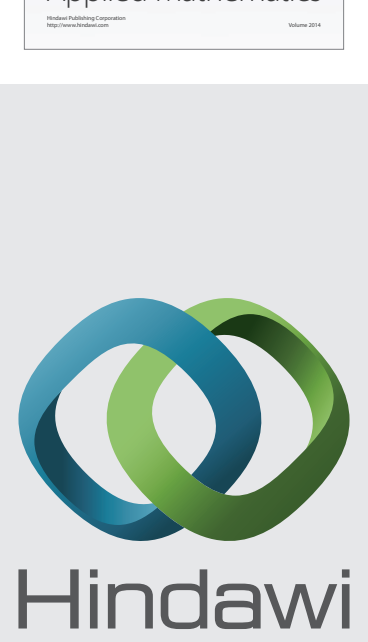

Submit your manuscripts at http://www.hindawi.com
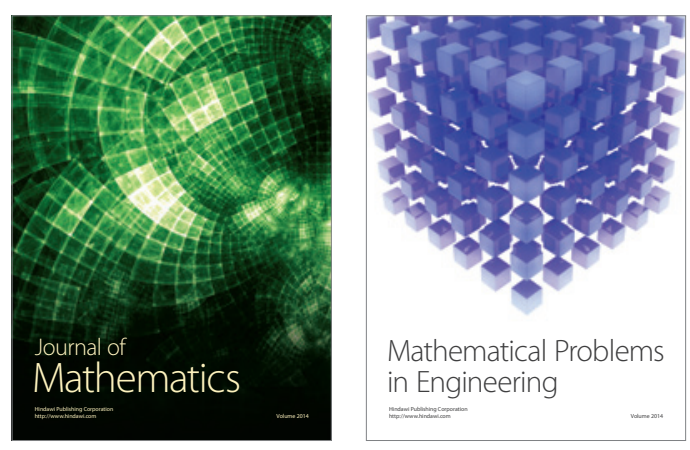

Mathematical Problems in Engineering
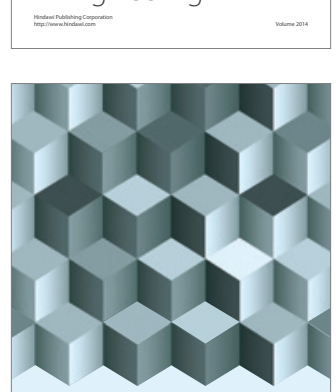

Journal of

Function Spaces
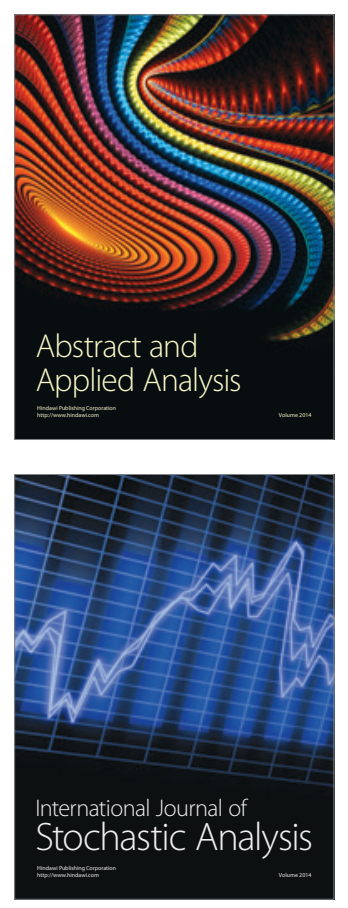

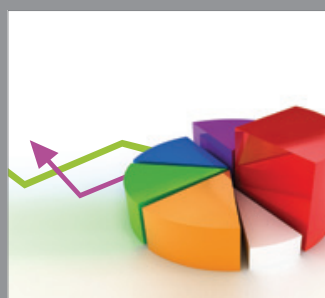

ournal of

Probability and Statistics

Promensencen
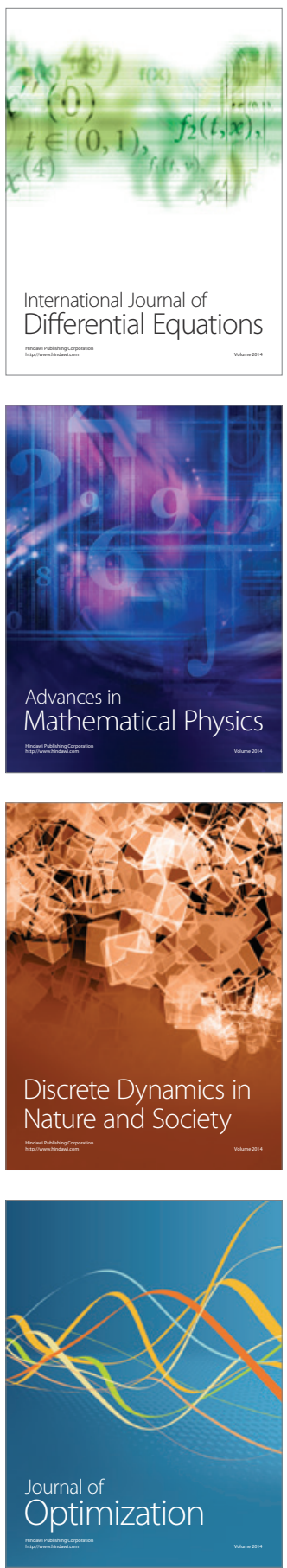